\title{
An Exploratory Study Of Antismoking Warning Labels And The Millennial Consumer
}

Patricia R. Loubeau, Iona College, USA

Chrissy M. Martins, Iona College, USA

\begin{abstract}
There has been debate over the inclusion of graphic antismoking warning labels on cigarette products. Despite prior research suggesting that graphic labels are effective in curtailing smoking among adult consumers, little insight exists about their effectiveness on younger consumers. In this research, we examine how different types of graphic warning labels can affect younger, "millennial" consumers. Our study explores 42 different warning labels (i.e., text-only, or based on disease, death, sexual dysfunction, or social consequences) on millennial consumers' attitudes about smoking. Results suggest that relatively more graphic labels demonstrating the health consequences of smoking were among the most effective in affecting these consumers' attitudes. These findings have implications for tobacco product packaging to promote the prevention and cessation of smoking by millennial consumers.
\end{abstract}

Keywords: Health; Antismoking; Public Policy; Graphic Health Warning

\section{INTRODUCTION}

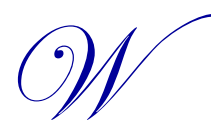

orldwide, almost 6 million people die from tobacco use each year, both from direct tobacco use and second-hand smoke. By 2020, this number will increase to 7.5 million, accounting for $10 \%$ of all deaths (www.who.int). In the United States, tobacco remains the leading cause of preventable morbidity and mortality (www.cdc.gov/tobacco). A comprehensive tobacco control strategy, including policy on taxation, tobacco promotion, nicotine replacement therapies, litigation against the tobacco companies, smoke-free public places and health promotion, is vital to persuade current smokers to quit and encourage younger individuals not to start (Novotny \& Mamudu, 2008).

According to the United States Food and Drug Administration (FDA), evidence demonstrates that the effectiveness of health warnings and messages increases with their prominence. In comparison with small, text-only warnings, larger warnings with pictures are more likely to be noticed, better communicate health risks, provoke a greater emotional response, and increase the motivation of tobacco users to quit and to decrease their tobacco consumption. Larger picture warnings are also more likely to communicate the full range and severity of health risks of smoking (Hammond, Fong, Borland, Cummings, McNeil, \& Driezen, 2007) and best promote smoking-related knowledge and smoking cessation (Thrasher, Hammond, Fong, Arillo-Santillan, 2007). Furthermore, research concludes that pictorial health warnings that elicit strong emotional reactions are significantly more effective than those that do not elicit a strong reaction (Hammond, 2011). Such graphic health warnings on cigarette packages are appealing both because of their unparalleled reach among smokers and their low cost to health educators.

In addition to general efforts directed at determining the best marketing strategy against smoking, there has been emphasis on developing messages geared for more at-risk consumers, especially given that research shows that health messages tailored to specific segments within a larger market are more effective (Andreasen, 1995). One such group of consumers is the young adult consumer market. These young adult, "millennial" consumers, defined as individuals between the ages of 16 and 34 (Barton, Fromm, \& Egan, 2012), exhibit large potential for the cigarette 
market. Statistics suggest that each day, roughly 4,000 individuals under the age of 18 smoke their first cigarette, and that nearly $80 \%$ of adult smokers began smoking before the age of 18 (www.cdc.gov/tobacco/youth). Thus, both researchers and policymakers alike have attempted to understand how to best educate and warn these consumers about the dangers of smoking. Though pictorial warning labels have been found to have a considerable effect on adult smokers, relatively little research has examined their impact on younger consumers. The goal of the current research was to explore how different types of graphic warning labels can affect millennial consumers. More specifically, the objective of this study was to determine specific themes that make warning labels effective for these consumers. It was proposed that millennials would be most affected by graphic labels depicting the health effects of cigarette smoking, especially given the increased presence and visibility of such advertisements in recent mainstream media (Hammond, Reid, Driezen, \& Boudreau, 2013).

\section{METHODS}

Participants who are considered millennial consumers from several undergraduate and graduate classes at a small Northeastern college were recruited for this study. These individuals were intentionally chosen as they were good representations of millennials within the appropriate age group. A total of 182 online surveys were administered. There were 17 surveys eliminated due to incomplete data, leaving a total of 164 usable surveys. The mean age of participants was 21.80 years, and 100 (64\%) were female.

Once on the online survey website, participants first saw a page containing the consent form briefly explaining the research and obtaining consent. They first answered several questions about their demographic characteristics, followed by questions about their personal and parental cigarette use history, as well as their attitudes toward the health hazards of smoking. Table 1 provides a summary of participants' smoking behavior characteristics. Participants were then shown a series of 42 different (i.e., text-only, or based on disease, death, sexual dysfunction, or social consequences) antismoking warning labels (U.K. Department of Health, 2007). The warning labels were presented to participants in a random order, and were shown one by one. Following the presentation of the 42 warning labels, participants were shown all of the 42 labels on a single page, and asked to choose which label they thought made them think the most of the effect of smoking on one's health, which they felt was the most effective in preventing them from smoking, and which they felt was the most effective in preventing people in general from smoking. Finally, participants were debriefed and thanked for their time.

\begin{tabular}{|c|c|}
\hline & Percent overall \\
\hline \multicolumn{2}{|l|}{ Parental smoking history } \\
\hline Had at least one parent who smoked & 53.0 \\
\hline Did not have at least one parent who smoked & 47.0 \\
\hline \multicolumn{2}{|l|}{ Personal smoking history } \\
\hline Never smoked before & 59.5 \\
\hline Smoked, but not in last 30 days & 19.0 \\
\hline Have smoked in the last 30 days & 21.5 \\
\hline \multicolumn{2}{|l|}{ Concern about the health effects of smoking } \\
\hline Not concerned at all & 7.5 \\
\hline Somewhat concerned & 13.1 \\
\hline Concerned & 23.8 \\
\hline Very concerned & 30.6 \\
\hline Extremely concerned & 25.0 \\
\hline
\end{tabular}

\section{RESULTS}

Each of the three questions was analyzed to obtain the top three rated images. For the question regarding which label participants felt demonstrated the most effect of smoking on one's health, the top three labels all 
involved graphic, physical, and grotesque consequences of smoking (i.e., throat lesion, damaged set of lungs, and rotted teeth). For the question about which label participants felt was the most effective in preventing them from smoking, the same three labels were chosen, albeit in a slightly different order (throat lesion, rotted teeth, and damaged set of lungs). For the last question about the most effective label that prevents people in general from smoking, participants chose two of the same labels from the previous two questions, and another one depicting a presumed smoker in an emergency room operating table. Figure 1 demonstrates these results. Interestingly, there is a similar pattern of selected images even when the sample is broken down into smoking status.

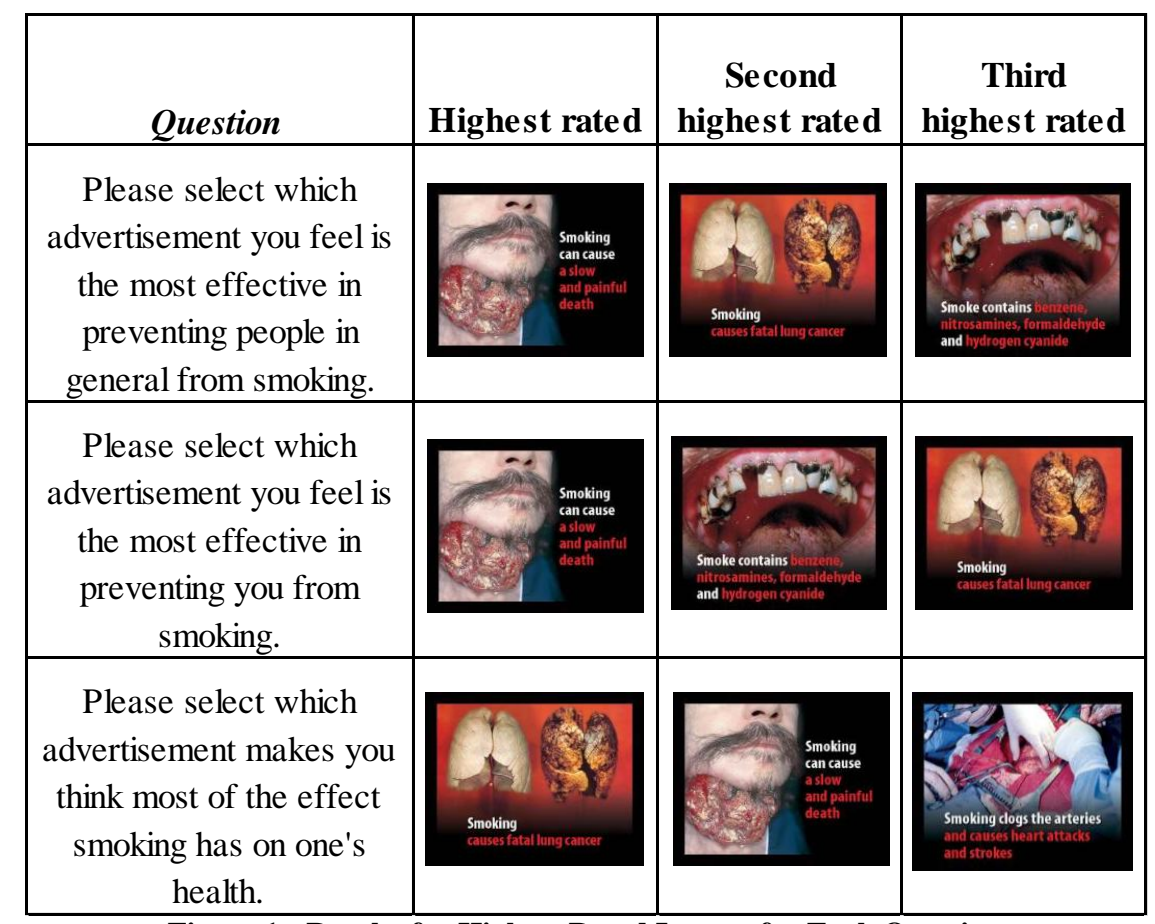

Figure 1: Results for Highest Rated Images for Each Question

\section{CONCLUSION}

While there is some research to suggest that graphic warning labels have a better effect on these younger consumers than other types of labels (i.e., text-only), little research has explored the types of graphic appeals most effective for millennials. In the current research, we explored the effect of various types of graphic warning labels on millennial consumers' attitudes about smoking. Interestingly, we find one theme in particular, namely the vivid, severe health consequences of smoking, to be the most effective for this group of consumers. From this knowledge, we hope to be able to better inform antismoking warning label legislation and policy directed at millennial consumers. In addition to the findings from this research, future research should examine some of the long-term effects of these relatively more effective warning labels. For example, are such warning labels better recalled over time, enough to continue to influence millennials' perceptions of the health risks of smoking? (Hammond et al., 2013) Given the tremendous efforts being made towards these consumers, these questions may be worth examining.

\section{AUTHOR INFORMATION}

Dr. Patricia R. Loubeau is a Professor in the Department of Marketing and International Business at Iona College. Her areas of specialization include marketing management, health care marketing, services marketing, market research, business perspectives and health policy analysis. Patricia R. Loubeau, Ph.D. Department of Marketing and International Business, Iona College, 715 North Avenue, New Rochelle, NY, 10801, USA. Phone: 914-633-2171. E-mail: ploubeau@iona.edu (Corresponding author) 
Dr. Chrissy M. Martins is an Assistant Professor in the Department of Marketing and International Business at Iona College. Her primary research interest focuses on the effect of health messages on various aspects of consumer behavior. Chrissy M. Martins, Ph.D., Department of Marketing and International Business, Iona College, 715 North Avenue, New Rochelle, NY, 10801, USA. Phone: 914-633-2422. E-mail: cmartins@iona.edu

\section{REFERENCES}

1. Andreasen, A.R. (1995) Marketing Social Change: Changing Behavior to Promote Health, Social Development, and the Environment. San Francisco: Jossey-Bass.

2. $\quad$ Barton, C. Fromm, J. Egan, C. (2012). The Millennial Consumer: Debunking stereotypes. Boston Consulting Group.

3. Hammond, D. (2011). Health warning messages on tobacco products: A review. Tobacco Control, 20, 327337.

4. Hammond D., Fong G.T., Borland R., Cummings K.M., McNeill A, Driezen P. (2007). Text and graphic warnings on cigarette packages: findings from the international tobacco control four country study. American Journal of Preventive Medicine, 32(3), 202-209.

5. Hammond, D., Reid, J.L., Driezen, P., \& Boudreau, C. (2013). Pictorial health warnings on cigarette packs in the United States: An experimental evaluation of the proposed FDA warnings. Nicotine \& Tobacco Research, 15(1), 93-102.

6. $\quad$ http://www.cdc.gov/tobacco/

7. $\quad$ http://www.cdc.gov/tobacco/youth/

8. http://www.who.int/mediacentre/factsheets/fs339/en/

9. $\quad$ Novotny T.E., Mamudu H.M. (2008). Progression of tobacco control policies: implications for global action and for tobacco control in developing countries. Washington, D.C.: World Bank.

10. Thrasher J.F., Hammond D., Fong G.T., Arillo-Santillán E. (2007). Smokers' reactions to cigarette package warnings with graphic imagery and with only text: a comparison between Mexico and Canada. Salud Publica de Mexico, 49, 233-40.

11. U.K. Department of Health. (2007). Consultation on the introduction of picture warnings on tobacco packs: Report on consultation. http://www.dh.gov.uk/health/category/publications/ reports-publications 